\title{
GESTÃO DEMOCRÁTICA DA EDUCAÇÃO SOB PERSPECTIVA COMPARADA BRASIL-PORTUGAL: ENTRE A EXIGÊNCIA LEGAL E A EXEQUIBILIDADE REAL
}

\author{
DONALDO BELLO SOUZA* \\ DORA FONSECA CASTRO ${ }^{* *}$
}

\begin{abstract}
RESUMO: Este artigo visa discutir, sob perspectiva comparada, alguns aspectos da gestão democrática da educação no Brasil e em Portugal, com base na revisão da literatura pertinente e dos marcos jurídicos que vieram regulá-la, problematizando a dicotomia entre a difusão do seu ideário e a sua concretização no campo das políticas públicas. Como conclusão mais geral, constata-se que, apesar de o poder central vir difundindo o discurso da descentralização nestes países, tudo leva a crer que o plano da retórica não logrou ser efetivamente superado, uma vez que, entre avanços e recuos deste processo, as tentativas vêm se constituindo em movimentos de alguma desconcentração de poderes, ainda marcados pela mesma lógica centralizadora.
\end{abstract}

Palavras-chave: Gestão democrática da educação. Descentralização da educação. Municipalização da educação. Educação comparada. Brasil-Portugal.

\section{Democratic MANAgEMENT OF EDUCATION FROM THE}

\section{Compared perspective of Brazil and Portugal: Between legal REQUIREMENTS AND REAL PRACTICABILITY}

ABSTRACT: This paper discusses, from a comparative perspective, selected features of democratic management in Brazilian and Portuguese Education by revising key literature and its legal framework, problematizing the dichotomy among the diffusion of its ideas and its actual operability among public policies. The general conclusion, notes that, although both central governments have emphasized the decentralization discourse, they have both failed to effectively overcome the rhetoric level, since advances and

\footnotetext{
* Pós-doutor em Política e Administração Educacional e professor associado na Faculdade de Educação da Universidade do Estado do Rio de Janeiro (UERJ). E-mail: donaldosouza@hotmail.com

* Pós-doutora em Administração Educacional e professora adjunta na Escola Superior de Educação (ESE) do Instituto Politécnico do Porto (IPPorto), Portugal. E-mail: doracastro@ese.ipp.pt
} 
setbacks in this process have constituted some movements of devolution of powers, they are still imprinted by the same centralized logic.

Key words: Democratic management of education. Decentralization of education. Municipalization of education. Compared education. BrazilPortugal.

\title{
GESTION DEMOCRATIQUe DE L'ÉDUCATION SOUS UNE PERSPECTIVE COMPARATIVE BRÉSIL-PORTUGAL: ENTRE L'OBLIGATION JURIDIQUE
}

\author{
ET LA PRATICABILITÉ RÉELLE
}

RÉSUMÉ: Cet article a pour but de débattre sous une perspective comparative certains aspects de la gestion démocratique de l'éducation au Brésil et au Portugal. Tout cela ayant pour base l'étude récapitulative appropriée et les cadres juridiques qui viennent la réglementer, remettant en cause la dichotomie entre la diffusion de ses idées et sa concrétisation dans le domaine des politiques publiques. Pour conclure d'une manière plus générale, on note que, malgré le discours de décentralisation que le gouvernement central répand dans ces pays, il semble que le niveau de la rhétorique n'ait pas réussi à être surmonté efficacement, car entre progrès et reculs de ce dossier les essais ont pris la forme de mouvements d'une certaine décentralisation de pouvoirs, encore déterminés par la même logique centralisée.

Mots-clés: Gestion démocratique de l'éducation. Décentralisation de l'éducation. Municipalisation de l'éducation. Éducation comparée. BrésilPortugal

\section{Introdução}

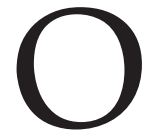

presente artigo visa discutir, sob perspectiva comparada, alguns aspectos da gestão democrática da educação no Brasil e em Portugal, tomando por foco de análise, em especial, os sistemas municipais de ensino, embora estabeleça algumas análises em relação ao rebatimento desta problemática no âmbito das unidades escolares, apoiando-se na revisão da literatura pertinente e nos marcos jurídicos que vieram regulá-la em ambos os países, problematizando, com isso, a dicotomia entre a difusão do seu ideário e a materialização no campo das políticas públicas locais.

A gestão democrática da educação está intrinsecamente ligada a conceitos de autonomia e descentralização. Mais autonomia e mais liberdade numa sociedade democrática passaria por uma "transferência ou devolução dos poderes e das liberdades usurpados e concentrados pelo e no Estado para novas entidades separadas e independentes dele" (Formosinho et al., 2010, p. 97). Contudo, tal como entende Lima (1999, p. 67), "sem competências ou poderes transferidos para as escolas, sem esquemas de descentralização regional ou municipal (em termos territoriais ou, mesmo apenas, funcionais), torna-se difícil compreender o discurso pretensamente 
descentralizador e autonómico". Ferreira (2012, p. 43) entende que a autonomia está intimamente ligada à democracia, "no sentido da proximidade e da partilha do poder pelos diferentes actores escolares" nos seus diferentes níveis de decisão e atuação.

Reconhecendo várias expressões da autonomia, Ferreira (op. cit., p. 45-47) fala-nos de algumas "facetas" de autonomia, a saber: i) a "autonomia requentada", que seria a autonomia apenas no plano ideológico e filosófico, não se assumindo efetivamente em práticas autônomas, ou seja, marcada pelo distanciamento entre discurso e ação; ii) a "quase-autonomia", que se desenvolve "em torno da mais-valia e da eficácia, descurando-se aspetos de desenvolvimento e partilha de poderes dos atores"; iii) a "autonomia redonda", que seria uma autonomia enformada na perspetiva formal e legal e que "se impõe numa lógica substântiva legitima e que, portanto, não serve às especificidades dos contextos escolares e dos atores"; iv) a "autonomia crísica", que revela o falhanço da própria implementação e desenvolvimento da autonomia imposta pelos normativos; e, por fim, v) a "autonomia sensata", que seria a desejável, pois "alicerça-se na dupla ideia de emancipação enquanto projeto de desenvolvimento pessoal e mudança societal". Estas "facetas" ou expressões da autonomia permitem-nos examinar os processos de (des)construção da gestão democrática em tempos e espaços de tensões, contradições e ambiguidades e, em especial, entre regulações e emancipações, aqui, particularmente, no Brasil e em Portugal (cf. Ferreira, 2012).

Os processos de autonomia e de descentralização têm vindo a ser reconfigurados ao longo dos tempos, cujas lógicas de variações Barroso (2011a, p. 45) identifica como: "estatal", "de mercado", "corporativa" e "sociocomunitária". Recuperamos neste texto três das quatro lógicas identificadas por Barroso e que, a nosso ver, contribuem para perceber como se foram desenvolvendo esses processos, sobretudo ao nível da produção legislativa e construção do quadro normativo que veio enquadrando as várias decisões políticas no Brasil e em Portugal. A "lógica estatal", que reduz os processos de reforço da autonomia a "uma simples modernização administrativa destinada a aliviar a administração central dos problemas de execução que não consegue resolver" (idem, ibid.), levando, como nos explica o autor, a um "ardiloso processo de re-centralização administrativa" (ibid.); a "lógica de mercado", na qual a autonomia é defendida como um instrumento para a "construção de um mercado educativo, descentralizado, concorrencial e autónomo" (idem, ibid.), tendendo à desrregulação da intervenção estatal; por fim, a "lógica sociocomunitária", a partir da qual a autonomia surge como "um processo social pelo qual os professores, os pais, os alunos e outros cidadãos se mobilizam (...) para, num quadro das orientações gerais de um sistema público nacional de ensino, obterem um compromisso e empreenderem uma acção colectiva - a construção de um projecto educativo e a prestação de um serviço público local de educação" (Barroso, op. cit., p. 46). 
A complexidade de que se revestem os processos de descentralização e a sua ligação com autonomia e outros conceitos que se avizinham têm vindo, portanto, a ser explorados por vários autores que nos têm revelado o lado mais oculto, deixando perceber as incongruências entre os discursos, as intenções e as práticas.

Discorrer sobre a gestão democrática e, sobretudo, acerca do seu desenvolvimento ou retrocesso é, inevitavelmente, voltar às questões da autonomia e da descentralização, mas também consiste em refletir-se sobre as mudanças de referenciais que afetaram a gestão escolar, promovendo mutações nas lógicas de "redistribuição de poderes entre o 'centro' e a 'periferia', com a recomposição do papel do Estado na regulação da educação e com novas formas de 'governança'” (idem, ibid., p. 28). Assim, a autonomia, a descentralização e a participação foram adquirindo novos sentidos ao longo destas últimas décadas, sendo esta situação ainda mais relevante em períodos de grande ambiguidade discursiva, como o atual, no qual o discurso democrático se mistura com o discurso gestionário. Fontoura (2008, p. 20) alerta-nos para o fato de algumas medidas contrariarem, na prática, o discurso da gestão democrática, pois "despojam a descentralização e a autonomia de sentido político democrático-participativo", revelando-se, sobretudo, as "suas concepções instrumentais do tipo gerencial, técnico-implementativo ou desregulador" (idem, ibid.). Ao reforçar esta ideia, Lima (2011a) chama a atenção para a existência de uma subordinação da democracia atual aos princípios gestionários e às lógicas de mercado.

\section{Descentralização da educação pela via da municipalização no Brasil e em Portugal}

Em linhas gerais, é possível afirmar que foi somente na segunda metade dos idos de 1990 que, coincidentemente às reformas educacionais em curso no Brasil pós-Lei de Diretrizes e Bases da Educação Nacional (LDB) n. 9.394/1996 -, se observou um apelo sistemático à adoção de medidas descentralizadoras de algumas das competências do governo central português no campo educacional, em que pese o fato de a Lei de Bases do Sistema Educativo (LBSE) n. 46/1986 tê-la preconizado em meados da década anterior, em paralelo a propostas também de participação e autonomia (Afonso, 2000; Lima, 2000).

No Brasil, a Constituição Federal (CF) de 1988, a par de um conjunto extenso de avanços que trouxe para a vida nacional, veio suscitar algumas importantes mudanças na legislação educacional, indo ao encontro das expectativas da sociedade brasileira em torno da elaboração de normas mais adequadas às transformações democráticas inauguradas no país a partir dos anos de 1980, em que pesem as tensões político-sociais e partidárias que se faziam presentes desde a Assembléia Nacional 
Constituinte (ANC), expressão do conflito de interesses que marca a diversidade socioeconômica e, por conseguinte, sociopolítica no Brasil.

No campo da educação, apesar das demandas sociais existentes, a regulamentação dos dispositivos constitucionais de 1988 só foi realizada oito anos depois, por intermédio da promulgação da LDB n. 9.394/96, cujo texto não apenas ratificou a organização sistêmica já praticada em larga medida em algumas regiões do país, como normatizou a condição de sistemas "autônomos" atribuída aos municípios por aquela CF. Com isso, a organização anterior, que considerava apenas três esferas governamentais (federal, estadual e Distrito Federal), passou a integrar este quarto ente federado, apontando para a autonomia relativa de seus respectivos sistemas e, ainda, diferenciando-os quanto às incumbências e prioridades, advogando, contudo, a prática do regime de colaboração entre eles. Tal concepção de colaboração passou formalmente a prever ações conjuntas entre os entes federados, abarcando, por exemplo: a divisão de responsabilidades pela oferta do ensino fundamental; o planejamento educacional (planos de educação e censos escolares); a superação de decisões impostas ou a simples transferência de encargos, sem que houvesse o repasse devido dos meios e recursos necessários; e, ainda, a garantia de participação da sociedade por meio dos conselhos, com representação popular e poder deliberativo (Abreu \& Sari, 1999; Oliveira \& Santana, 2010).

Entretanto, ao longo da década de 1990, as políticas governamentais passaram a adotar o caminho da racionalidade financeira (Saviani, 1999), implicando redução dos gastos públicos e do tamanho do Estado, assim como a intensificação da abertura do país ao capital financeiro internacional. A partir disso, o uso instrumental do conceito de descentralização passou a ser, majoritariamente, aplicado como desconcentração (Cassasus, 1995), implicando processos de privatização, terceirização ou publicização dos serviços públicos (Adrião \& Peroni, 2008), com forte apelo às práticas sociais voluntárias de apoio à escola, de caráter tipicamente assistencial (Calderón \& Marim, 2003), mas com elevado controle dos níveis superiores do governo sobre os fluxos financeiros e as transferências de recursos intergovernamentais (Gonçalves, 1998), visivelmente ancorado na manutenção da centralização normativa e política em relação à instância executora (Montaño, 2003; Vieira \& Farias, 2007).

Contudo, conforme mais adiante evidenciado, no Brasil, ao contrário de Portugal, o processo dito descentralizador tenderá a repercutir, mais rapidamente, numa maior responsabilização direta do município na captação de recursos para o atendimento de suas próprias demandas, no monitoramento de gastos e na inspeção do cumprimento das metas federais e/ou estaduais estabelecidas, agora não unicamente pelo poder público local, mas, também, pela via da responsabilização da sociedade civil (Jacobi, 2008; Menezes, 2001; Nogueira, 1997). 
Por seu turno, a análise relativa aos processos de desenvolvimento da descentralização da educação em Portugal revela que, a partir de finais dos anos de 1980, começou a esboçar-se uma clara intenção de a administração educacional abandonar a prática de tomada de decisões uniformizantes em nível central (Formosinho \& Machado, 2000), herança do período do Estado Novo em Portugal (1933-1974), neste último caso momento no qual a relação autoritária do poder central com a escola veio a atingir o seu auge, implicando, entre outros aspectos, retirada dos poderes dos municípios sobre a administração das escolas primárias (Pires, 2003).

A publicação da LBSE 46/86 pode ser tomada como um marco significativo, em termos legislativos, para o desenvolvimento das ideias de participação e descentralização, na medida em que recusa o modelo burocrático e centralizado de administração na sua forma concentrada. Formosinho e Machado (2000) também dão-nos conta de que esta lei define os princípios a que deveria obedecer a administração e gestão educativa ao nível central, regional autônomo, regional, local e de estabelecimento. Esta LBSE, que, segundo Lima (1992), à época, obteve consenso entre os partidos políticos, acabou, no entanto, por contribuir para a implementação de medidas destinadas à promoção de formas de desconcentração dos serviços de educação em Portugal e não necessariamente descentralizadoras, a exemplo do que veio a acontecer, igualmente, no Brasil.

Em prol da descentralização anunciada em vários normativos legais, na década de 1990, intensificou-se apenas a desconcentração da educação com a transferência de competências da administração central para estruturas de gestão intermédia: as Direções Regionais de Educação (DREs) e Centros de Área Educativa (CAEs). Nestes termos, o Decreto-Lei n. 141/1993 determinou que as DREs constituíssem serviços regionais do Ministério de Educação (ME), dotados de autonomia administrativa, que viessem assegurar a orientação, coordenação e apoio às escolas de ensino não superior ao nível regional. Para Afonso (2006), essas DREs passaram a representar instâncias de regulação intermédia da educação, ao passo que os CAEs, um prolongamento das estruturas anteriores que, em seu conjunto, acabaram por contribuir para a manutenção de uma lógica de funcionamento ainda hierarquizada e burocratizada.

Com o reordenamento escolar e o surgir de novas tipologias organizacionais, observa-se uma sobreposição das competências e funções dos vários órgãos de gestão dos diferentes níveis de decisão. Possivelmente devido a esse fato, mas também, porventura, em virtude da assunção (em especial no plano dos discursos políticos) da autonomia dos agrupamentos de escolas, os CAEs, estruturas de gestão intermédia e periférica, começaram a extinguir-se, ficando apenas em funcionamento as várias DREs. 
Assim, em termos esquemáticos, podemos identifcar diferentes níveis de gestão da educação em Portugal: ao nível central, os serviços do ME (serviços da administração central); ao nível regional, as DREs e, na instância local, os Agrupamentos de escolas, embora na fase de formação destes últimos, aqueles outros níveis não tenham se mostrado facilitadores do processo de descentralização da educação (Pinhal \& Dinis, 2002), uma vez que a administração central os utilizou para retomar o controle quase absoluto sobre o sistema educativo, mais uma vez revelando a faceta de um Estado centralizador, controlador e burocrático.

Contudo, estudos realizados ao nível da administração educacional (Costa, 2007, 2009; Lima, 1992) levantam algumas dúvidas a respeito do quadro ora traçado. Várias investigações realizadas no plano da ação dos atores, nas diferentes instâncias das organizações educativas, vão mostrando que a ação se pode afastar do estabelecido ou do previsto. Nesse sentido, poder-se-ia afirmar que, à margem das estruturas formais que apontam para cadeias hierárquicas que promovem regulações no sentido descendente vertical e que à partida dificultariam o desenvolvimento da autonomia das organizações educativas, uma face mais oculta e que diz respeito às dinâmicas reais dos atores sociais, parece revelar muitas ambiguidades e contradições, mostrando que os processos de desenvolvimento de autonomia não são movimentos lineares dependentes exclusivamente das estruturas formais. Em determinadas realidades, parecem emergir regulações no sentido das periferias para os centros de poder instituídos, e que nos remetem para a consideração da existência de outros centros de decisão e de espaços de autonomia administrativa e pedagógica.

Com o Decreto-Lei n. 7/2003, foram reativados, apenas ainda no plano legal, os Conselhos Municipais de Educação (CMEs) no país, com algumas debilidades no que diz respeito à representatividade das diferentes forças sociais, econômicas e políticas do território educativo, mas, em alguma medida, tendendo à valorização da "capacidade política, de decisão e gestão dos municípios portugueses" e contribuindo para a "concretização de um poder local mais forte" (Formosinho \& Machado, 2005, p. 152).

Atualmente, numa lógica de redução de estruturas e de racionalização de recursos, perspectiva-se a extinção das DREs, ao mesmo tempo em que se discutem possibilidades de transferir algumas competências destas estruturas para os poderes locais (municípios), conforme será destacado mais adiante.

\section{Gestão democrática da educação no Brasil em Portugal}

Conforme anteriormente visto, a CF de 1988 outorgou autonomia relativa aos municípios brasileiros, cujos reflexos na área da educação vieram implicar possibilidade de formulação e regulamentação de suas próprias políticas educacionais, com 
reflexos diretos na cobertura, especialmente, da educação infantil e do ensino fundamental. Naquele momento, marcado por fortes reações ao centralismo do regime militar dos anos de 1960 e 1970, e apesar da pluralidade de interesses, definiram-se importantes tendências de valorização do poder local, reiteradas, alguns anos após, no campo da educação, pela nova LDB n. 9.394/96.

Dessa maior autonomia, pelo menos proclamada, emergiram inúmeros desafios à gestão da educação municipal pública no Brasil, quer em termos das novas relações que viriam a ser estabelecidas junto aos demais entes federados - por exemplo, pela via do regime de colaboração -, quer no que concerne aos vínculos a serem (re)estabelecidos com a sociedade civil local, particularmente no que remete à participação popular em órgãos colegiados diversos.

Contudo, foi nos idos de 1990 que se observou, com maior nitidez, a estruturação de novas redes associativas (Gohn, 2001), entre as quais a criação de conselhos nas diversas áreas das políticas públicas do país, amparados por ampla base legal, assumindo diversos formatos e funções, sendo caracteristicamente compostos por representantes do poder público e da sociedade civil como, por exemplo, as iniciativas que se relacionam à criação dos conselhos de direitos, de assistência social, de saúde, de educação, entre outros. No campo da educação básica local, disseminam-se, na esfera dos seus sistemas municipais, os CMEs e os Conselhos de Acompanhamento e Controle Social (Cacs) e, no âmbito das suas unidades escolares, os conselhos escolares, os conselhos de classe e de série, os grêmios estudantis, entre outros (Souza, 2006).

De um modo geral, a existência desses órgãos colegiados passa a ser tratada oficialmente como garantia da consolidação de uma gestão da educação dita democrática, a par das condições reais do seu funcionamento e, em especial, do nível e grau de participação (Bordenave, 1994) efetiva da sociedade civil, seja em seu colegiado, seja na plenária. Contudo, do ponto de vista crítico, diversos estudos vêm apontando inúmeros problemas na sua criação, implantação e funcionamento institucional e político local. No que remete aos CMEs e aos Cacs, Souza (2006) e Souza e Vasconcelos (2006) identificaram que as pesquisas existentes se preocupam sobremaneira com a qualidade da participação da sociedade civil em ambos os Conselhos, caracteristicamente débil, sugerindo certo descrédito em relação às possibilidades de funcionamento regular dessas instâncias, assim como em relação à possibilidade de estarem contribuindo de modo efetivo para o processo de emancipação social local.

Pelo fato desses Conselhos não terem localmente emergido em virtude de uma tomada de consciência sociopolítica local, e sim por força de lei federal e/ou municipal, em larga medida podem ser tomados como expressão de políticas que, a 
partir dos idos de 1990, visaram a desoneração do Estado de sua obrigação para com a área social, transferindo determinadas responsabilidades para a sociedade civil, de modo particular apelando para sentimentos como os de solidariedade, como no caso do trabalho voluntário que se realiza em muitas instituições escolares públicas (Calderón \& Marim, 2003). É também consensual o fato de que a lei atribui a esses Conselhos função relativamente complexa, que demanda por parte dos seus membros elevado preparo, tempo e acesso a documentações detalhadas sobre a matéria, e que, na realidade da maioria das localidades que vêm sendo investigadas, a sua criação ocorre por intermédio de nomeações realizadas pelos prefeitos, comprometendo a construção da autonomia entre os conselheiros e, consequentemente, a do funcionamento sociopolítico deste próprio órgão dito colegiado. No caso específico dos CMEs, nota-se, ainda, a prevalência da função deliberativa em detrimento da função consultiva e, sobremaneira, da fiscalizadora (Souza \& Vasconcelos, 2006).

Em meio ao contexto já descrito, novos arranjos de gestão escolar irão surgir, pelo menos declaradamente orientados segundo princípios da gestão democrática, com foco na construção da autonomia administrativa, pedagógica e financeira dessas instituições e, em paralelo, propugnando o envolvimento crescente de professores, de funcionários, de alunos e de seus pais, a par da comunidade local, especialmente por intermédio de determinadas estruturas de gestão colegiadas, como os conselhos de escola, ou pela via da construção coletiva do projeto político-pedagógico (PPP) da instituição escolar.

No entanto, de acordo com outros estudos recentemente desenvolvidos (Souza, 2011), a problemática da gestão democrática da escola vem sendo tratada de modo não necessariamente crítico como, por exemplo, no que remete às discussões sobre a descentralização e a participação sociopolítica, pois frequentemente ocorre a associação direta entre descentralização, democracia e participação social, como se houvesse uma mútua e imediata dependência entre essas dimensões - conforme nos alerta Nogueira (1997) -, o que leva alguns autores, mediante a identificação empírica de um ou outro desses aspectos, a considerar os demais implicitamente presentes ou necessariamente ausentes nos seus contextos de investigação. Neste quadro, as associações de pais e mestres (APM), os conselhos de escola, os grêmios estudantis e o PPPs despontam, por exemplo, como importantes componentes da gestão democrática.

Ainda de acordo com aqueles estudos (Souza, 2011), o processo de democratização das unidades escolares, ancorado nos componentes ora mencionados, deve tomar por foco a questão da participação sociopolítica (Gohn, 2001) nos processos decisórios levados a efeito no interior daqueles órgãos colegiados, isto como forma concreta de construção de espaços democráticos, cuja experiência, para além dos muros da instituição escolar, pode contribuir para a consolidação de uma cultura democrática de maior amplitude social, pois tende a envolver diversos atores sociais, 
tanto aqueles diretamente à frente dos processos educacionais formais, quanto pertencentes às comunidades atendidas pela instituição escolar, conforme já sinalizado.

De qualquer modo, ainda são muitos os desafios e dificuldades existentes no Brasil em torno da participação sociopolítica também na instância escolar, seja na perspectiva de se aumentar a gama de representatividade em seu interior, de modo a incluir sujeitos de diferentes idades, saberes e gênero - embora se reconheça que, quanto maior a quantidade de membros por categoria, menor as possibilidades de participação -, seja em termos do reconhecimento das tensões que marcam tal processo, particularmente diante da ingerência política de determinados órgãos pertencentes ao sistema local de educação, como, por exemplo, as próprias Secretarias Municipais de Educação (SMEs). Tradicionalmente, o processo decisório esteve centrado na direção da instituição escolar, o que significa não ser fácil o seu deslocamento para a esfera coletiva, embora se reconheça que se trata de uma questão processual e não imediata.

Já em Portugal, a revolução de 25 de abril de 1974 marca o início do período denominado de renovação ideológica. Os ideais da democracia emergem procurando desenvolver a participação, a cooperação e partilha de poderes ao nível social e educativo. O regime autoritário obstaculizava o desenvolvimento da autonomia local, configurando os municípios como prolongamentos do poder central. A Constituição da República Portuguesa de 1976 vem institucionalizar o regime democrático desencadeado por esta revolução, consagrando a descentralização administrativa como garantia do exercício democrático do poder (Formosinho \& Machado, 2005), de modo a favorecer o desenvolvimento dos territórios e dos órgãos de poder local.

Em matéria de valorização da escola democrática, e no que diz respeito ao discurso político-normativo, podemos salientar, além da LBSE, a Lei n. 31/1987. Lima (1992) entende que os conteúdos democráticos e participativos estão muito presentes na LBSE, ao passo que Formosinho e Machado (2005, p. 115) consideram que esta última lei inclui "uma distribuição de poder nas decisões educativas, através da descentralização dos órgãos e da participação popular na definição da política e na direção e gestão dos estabelecimentos de ensino". No artigo 43 da Lei n. 31/1987, podemos ler que o sistema educativo é constituído por estruturas de âmbito nacional, regional autônomo, regional e local, salientando-se que estas estruturas deveriam ser descentralizadas e desconcentradas. Em termos gerais, dizemos que neste diploma passam a estar previstas formas de descentralização e desconcentração da administração educativa, promovendo a possível regionalização do território nacional.

A par dos processos de regulação transnacional por que veio a passar Portugal junto com demais países da Comunidade Europeia (CE), em especial a partir 
dos anos de 1990, com forte apelo à autonomia local, o Decreto-Lei n. 115-A/1998, que instaura o Regime de Autonomia, Administração e Gestão das Escolas em Portugal, veio também contribuir para a valorização do espaço local, ainda que não numa perspetiva de território, mas caracteristicamente situada ao nível da escola. A partir daí, é posível afirmar que os órgãos de gestão das unidades organizacionais educativas passam a contar com uma presença mais significativa de membros da comunidade educativa, quer no conselho pedagógico, quer na assembléia de escola. Mais recentemente, o Decreto-Lei n. 75/2008 veio reforçar esta situação, pois prevê, ao nível do Conselho Geral (órgão de topo das escolas/agrupamentos de escolas), a integração de várias dimensões da comunidade educativa, incluindo elementos dos municípios.

Ao mesmo tempo em que se sucediam mudanças significativas, em termos legislativos, ao nível da gestão dos estabelecimentos de educação, iam, paralelamente, ocorrendo mudanças nos órgãos de gestão num plano mais territorial. Em 1998, são formalizados os Conselhos Locais de Educação (CLE), preconizados como órgão fundamentalmente consultivo, com a vocação para formulação de pareceres, recomendações e propostas, ficando, contudo, limitado na sua ação, uma vez que passa tipicamente a se caracterizar, em muitos dos casos, pela legitimação do que já fora decidido ou mesmo implementado na esfera de outros órgãos (Santos, 2004).

Em substituição ao CLE, surgiu, com a publicação do Decreto-Lei n. 7/2003, o CME, que regulamenta, também, a criação e desenvolvimento das Cartas Educativas. Este "novo" órgão continua a ter um papel predominantemente consultivo, como o seu antecessor. Estudos realizados, recentemente descrevem o CME como um órgão com pouco poder de coordenação das políticas educativas locais e que continua a ter um papel direcionado para a legitimação de decisões ou ações já tomadas ou em curso. Contudo, Oliveira (2009) entende, num estudo recente, desenvolvido junto aos CMEs no distrito de Aveiro, que há consenso no entendimento do CME como instrumento fundamental ao serviço da descentralização. $O$ mesmo autor adianta que, "de uma maneira geral, pode-se concluir que este órgão necessita de conquistar o seu próprio espaço e a sua legitimidade no 'terreno'", visando superar algumas ambiguidades e dotá-lo “de maior capacidade de articulação/coordenação" (p. 116).

Nestes últimos tempos, temos vindo a assistir a algumas ações que nos permitem afirmar que estamos no caminho da afirmação da desconcentração de poderes em matéria de educação. Têm vindo a estabelecer-se acordos e protocolos entre o ME e a Associação Nacional de Municípios Portugueses (ANMP) sobre várias matérias, nomeadamente a partilha de responsabilidades no que diz respeito à ação social escolar, à oferta formativa, à gestão dos transportes, refeições, espaços e equipamentos escolares e à própria construção das Cartas Educativas. A exemplo disso, em 2004 foi celebrado um Protocolo entre aqueles órgãos que parte da assunção do Decreto-Lei 
n. 7/2003 como "passo fundamental no sentido da concretização da descentralização administrativa na área da educação", constituindo-se como um normativo capital para a "execução da descentralização e territorialização de políticas educativas, para o que conta com dois instrumentos fundamentais: o conselho municipal de educação e as cartas educativas." O protocolo contempla a articulação entre a administração central, central desconcentrada e cada um dos municípios para a elaboração e aprovação do modelo das Cartas Educativas, assim como em relação às regras de criação, desenvolvimento e monitorização das mesmas.

Em termos gerais, a territorialização ou municipalização da educação em Portugal vem revelando, em diversas investigações, que: i) a intervenção do município é ainda limitada (Pinhal, 2004); ii) a descentralização é essencialmente uma figura de retórica (Barroso, 1999; Formosinho \& Machado, 2004); iii) a organização e as medidas tomadas têm sido avulsas, ambíguas e, muitas vezes, contraditórias; iv) tem existido uma política ambígua no que diz respeito à territorialização educativa, criando ao nível local tensões entre as escolas/agrupamentos de escolas e municípios (Guedes, 2002; Machado, 2004); v) a regulamentação dos CMEs constitui um retrocesso em termos de "participação contextualizada" (Cruz, 2007, p. 69) e que, em última instância, vi) tem vindo a contribuir para controlar o desenvolvimento das políticas educativas definidas pelo poder central (Oliveira, 2009; Ribeiro, 2005).

Ao nível das unidades organizacionais escolares (escolas não agrupadas ou agrupamentos de escolas), recentemente, o Decreto-Lei n. 75/2008 veio reforçar a participação da comunidade local em Portugal, pois prevê, ao nível do Conselho Geral, a integração de vários membros da comunidade educativa, incluindo aqueles das câmaras municipais. Contudo, tal como ressalta Barroso (2011a, p. 34), na "ausência de um processo claro de descentralização, a intervenção das autarquias na gestão interna das escolas acaba por ter um efeito reduzido e não ser muito valorizada pelos próprios autarcas". Este mesmo normativo viria a consagrar a liderança unipessoal na figura de diretor, acabando com os conselhos executivos, órgãos de natureza colegial, implicando considerar a existência de um recuo na gestão democrática da escola portuguesa. A importância que é atribuída, "nos normativos legais, ao reforço da liderança formal unipessoal bem como a necessidade da sua responsabilização pelo desempenho da instituição anuncia o abandono, em termos legislativos, das lideranças colegiais partilhadas" (Castro, 2011, p. 17). A um só tempo, o recuo ao nível da gestão democrática nas escolas vem determinar que as lideranças intermédias (como os coordenadores de estabelecimento e coordenadores de departamento) sejam nomeadas pelo diretor, deixando por isso de ser eleitas pelos seus pares. Todavia, a figura de diretor como uma liderança forte tem vindo a revelar que, na prática, e devido a múltiplos jogos de poder, o diretor pode ser considerado uma liderança formal mais forte para dentro da organização e mais fraca para 
fora dela, se comparada com o "velho" conselho executivo (Barroso, 2011b; Lima, $2011 b$ ), pondo em risco o desenvolvimento de processos efetivos de autonomia e de desenvolvimento de políticas educativas locais, e tendo em conta a participação sociopolítica.

As incongruências entre o plano dos discursos politico-normativos e o plano da ação desenvolvido pelas medidas tomadas pelo poder central acabam por não permitir avanços significativos no processo de desenvolvimento do poder local. O discurso da racionalização, que acaba por imperar, tem criado tensões entre o global e o local, o que, para alguns autores, tem contribuido mais para a recentralização do que para a almejada descentralização. Formosinho (2005, p. 26) entende que a "Administração central tem vindo a 'vender' desconcentração por descentralização, combinando uma retórica descentralizadora com normativos meramente desconcentrados (ou mesmo recentralizadores)".

O discurso político que vem legitimando o desenvolvimento do poder local tem, também, vindo a mudar. Gradualmente e por influências das lógicas gerencialistas, fruto das políticas neoliberais que têm vindo a ganhar força na Europa, o discurso da descentralização parece servir a "novos" princípios. A participação das comunidades para o desenvolvimento de um "bem comum" dá agora lugar a princípios de natureza gestionária, como a necessidade de modernização, de competitividade, de concorrência, de eficácia e eficiência, nos moldes propugandos pelo ideário neoliberal.

Apesar de haver um discurso político-normativo favorável ao desenvolvimento da descentralização e territorialização das políticas educativas, podemos perceber que o processo é comandado pelo poder central, que continua a regular, fortemente, os órgãos e instrumentos de gestão educativa ao nível local. A este respeito, Baixinho (2008, p. 6) diz-nos que, "ao limitar, pela imposição da lei, a composição do CME, presidência e distribuição de serviço, o Estado centraliza juridicamente e impôe uma normalização nacional para este órgão", o mesmo acontecendo, acrescentamos nós, com as Cartas Educativas, tendo em vista que, para a sua criação, desenvolvimento e monitorização, o Estado tem vindo a determinar os atores, processos e instrumentos.

\section{Considerações finais}

À guisa de conclusão, é possível afirmar que as contradições que vêm demarcando os processos de descentralização da educação no Brasil e em Portugal caracterizam a própria natureza desses Estados que, embora distintos (no Brasil, de estrutura federativa, e em Portugal, unitária), possuem muitas leis supostamente democráticas, embora tendam a manter práticas autoritárias seculares e excludentes, 
não garantindo, até o presente momento, a possibilidade de uma emancipação local qualificada, quer do ponto de vista dos sistemas de ensino e de suas unidades escolares, quer no que remete a uma maior participação social no processo decisório, de forma a inclinar-se para uma democracia de caráter cooperativo.

Em que pesem algumas diferenças substantivas, a descentralização da educação e o desenvolvimento de políticas educativas ao nível local no Brasil e em Portugal parecem ter, agora, um novo enquadramento. A descentralização ressurge a partir dos anos de 1990 como a possibilidade de Estado mínimo e mercado máximo, percebendo-se um afastamento das ideias da difusão da democracia participativa e do desenvolvimento dos territórios numa perspetiva sociocomunitária.

A participação e a colaboração, portanto, passam a ser associadas no discurso político-normativo a termos como competitividade, eficácia e eficiência, constituindo-se, dessa forma, em instrumentos ao serviço das lógicas gerenciais neoliberais, revelando que a democratização, embora não abandonada, sofre ressignificações coerentemente à racionalidade econômica hegemônica que organiza/desorganiza o modo de produção capitalista atual, a par dos múltiplos sentidos aos quais as concepções de democracia, histórico e socialmente, estiveram sujeitas.

As diferentes faces da autonomia identificadas por Ferreira (2012), bem como as lógicas de autonomia indicadas por Barroso (2011a), ajudam a perceber como a gestão democrática veio sendo resignificada em ambos os países, dando a entender que ainda se está muito afastado da lógica sociocomunitária e da autonomia sensata que permitiriam possivelmente o desenvolvimento de processos mais democráticos e emancipatórios, contribuindo, em consequência, para uma gestão mais participativo-democrática no campo da política e administração educacional.

As medidas que vão sendo implementadas pelo poder central, agora aliado das forças do mercado, acabam por despolitizar, em ambos os países, os processos de autonomia e descentralização, deixando em destaque a visão instrumental e tecnocrática, condicionando dessa forma o desenvolvimento de movimentos emancipatórios das periferias diante dos centros de decisão, não obstante marcados por profundas contradições nas e pelas quais, social e historicamente, se pode atuar.

\section{Referências}

ABREU, M.; SARI, M.T. Colaboração entre União, estados/DF e municípios na área da educação. Cadernos Aslegis, Brasília, DF, v. 3, n. 8, p. 9-15, maio/ago. 1999.

ADRIÃO, T.; PERONI, V. (Org.). Público e privado na educação: novos elementos para o debate. São Paulo: Xamã, 2008. 
AFONSO, A.J. Políticas educativas em Portugal (1985-2000): a reforma global, o pacto educativo e os reajustamentos neo-reformistas. In: CATANI, A.; OLIVEIRA, R.P. (Org.). Reformas educacionais em Portugal e no Brasil. Belo Horizonte: Autêntica, 2000. p. 17-40.

AFONSO, N. A direcção regional de educação: um espaço de regulação intermédia. In: BARROSO, J. (Org.). A regulação das políticas públicas da educação: espaços, dinâmicas e actores. Lisboa: Educa, 2006. p. 71-96.

BAIXINHO, A.F. Educação e autarquias: lógicas de ação do poder autárquico face ao poder central e aos micropoderes locais. In: CONGRESSO PORTUGUÊS DE SOCIOLOGIA, 6., 2008, Lisboa. Anais... Lisboa: Universidade Nova de Lisboa, Faculdade de Ciências Sociais e Humanidades, 2008. p. 1-13.

BARROSO, J. A escola entre o local e o global: perspectivas para o século XXI; o caso de Portugal. In: BARROSO, J. (Org.). A escola entre o local e o global: perspectivas para o século XXI. Lisboa: Educa, 1999. (Educa-Organizações, 4). p. 129-142.

BARROSO, J. Conhecimento e acção pública: as políticas sobre a gestão e autonomia das escolas em Portugal (1986-2008). In: BARROSO, J.; AFONSO, N. (Org.). Políticas educativas: mobilização de conhecimento e modos de regulação. Vila Nova de Gaia: Fundação Manuel Leão, 2011a. p. 27-58.

BARROSO, J. Direcção de escolas e regulação das políticas: em busca do Unicórnio. In: NETO-MENDES, A.; COSTA, J.A.; VENTURA, A. (Org.). A emergênncia do diretor da escola: questões políticas e organizacionais. Aveiro: Universidade de Aveiro, 2011b. p. 11-22.

BORDENAVE, J.E.D. O que é participação. 8. ed. São Paulo: Brasiliense, 1994.

BRASIL. Constituição (1988). Constituição da República Federativa do Brasil. Brasilia, DF: Senado Federal, 1988.

BRASIL. Lei n. 9.394, de 20 de dezembro de 1996. Estabelece as Diretrizes e Bases da Educação Nacional. Diário Oficial da União, Brasília, DF, 23 dez. 1996.

CALDERÓN, A.I.; MARIM, V. Participação popular: a escola como alvo do terceiro setor. In: SOUZA, D.B.; FARIA, L.C.M. (Org.). Desafios da educação municipal. Rio de Janeiro: DP\&A, 2003. p. 211-231.

CASSASUS, J. Tarefas da educação. Campinas: Autores Associados, 1995.

CASTRO, D. Os projetos de intervenção dos diretores de escola: uma construção discursiva a partir das regulações do discurso político-normativo. Sensos, Porto, v. 1, n. 2, p. 9-28, 2011. 
COSTA, J.A. Projectos em educação: contributos de análise organizacional. Aveiro: Universidade de Aveiro, 2007.

COSTA, J.A. Do direito à hipocrisia organizada na gestão das escolas. In: SIMPÓSIO BRASILEIRO, 24., CONGRESSO INTERAMERICANO DE POLÍTICA E ADMINISTRAÇÃO DA EDUCAÇÃO, 3., 2009, Vitória. Anais... Rio de Janeiro: Anpae; Ufes, 2009. p. 1-11. (CD-ROM).

CRUZ, C. Conselhos municipais de educação: política educativa e acção pública. Sísifo - Revista de Ciências de Educação, Lisboa, n. 4, p. 67-76, out./dez. 2007.

FERREIRA, E. (D)enunciar a autonomia: contributos para a compreensão da génese e da construção da autonomia escolar. Porto: Porto, 2012.

FERREIRA, F.I. O local em educação: animacão, gestão e parceria. Lisboa: Fundação Calouste Gulbenkian, 2005.

FONTOURA, M.M. Política e acção pública: entre uma regulação centralizada e uma regulação multipolar. Revista Portuguesa de Educação, Braga, v. 21, n. 2, p. 5-31, 2008.

FORMOSINHO, J. Centralização e descentralização na administração da escola de interesse público. In: FORMOSINHO, J. et al. (Org.). Administração da educação: lógicas burocráticas e lógicas de mediação. Porto: ASA, 2005. p. 13-52.

FORMOSINHO, J.; MACHADO, J. Autonomia, projeto e liderança. In: COSTA, J.A.; NETO-MENDES, A.; VENTURA, A. (Org.). Liderança e estratégia nas organizações escolares. Aveiro: Universidade de Aveiro, 2000. p. 185-199.

FORMOSINHO, J.; MACHADO, J. Evolução das políticas e da administração da educação em Portugal. Revista do Forum Português de Administração Educacional, Lisboa, n. 4, p. 6-31, 2004.

FORMOSINHO, J.; MACHADO, J. A administração da escola de interesse público em Portugal: políticas recentes. In: FORMOSINHO, J. et al. (Org.). Administração da educação: lógicas burocráticas e lógicas de mediação. Porto: Asa, 2005. p. 115-162.

FORMOSINHO, J. et al. Os (des)caminhos da autonomia das escolas. In: FORMOSINHO, J. et al. (Org.). Autonomia da escola pública em Portugal. Vila Nova de Gaia: Fundação Manuel Leão, 2010. p. 91-119.

GOHN, M.G. Conselhos gestores e participação sociopolítica. São Paulo: Cortez, 2001. (Questões da nossa época, 84).

GONÇALVES, R.A. O financiamento da educação: um sistema em desequilíbrio. Cadernos de Pesquisa, São Paulo, n. 103, p. 14-52, mar. 1998. 
GUEDES, G. As politicas educativas municipais na área metropolitana de Lisboa: o caso dos projectos sócio-educativos. 2002. 233f. Dissertação (Mestrado) - Faculdade de Psicologia e de Ciências da Educação, Universidade de Lisboa, Lisboa.

JACOBI, P.R. Participação, cidadania e descentralização: alcances e limites da engenharia institucional. In: SOUZA, D.B. (Org.). Conselhos municipais e controle social da educação: descentralização, participação e cidadania. São Paulo: Xamã, 2008. p. 115-130.

LIMA, L.C. A escola como organização e a participação na organização escolar. Braga: Universidade do Minho; Instituto de Educação e Psicologia; Centro de Estudos em Educação e Psicologia, 1992.

LIMA, L.C. Modernização, racionalização e optimização: perspectivas neotaylorianas na organização e administração da educação. Cadernos de Ciências Sociais, Porto, n. 14, p. 119-139, 1994.

LIMA, L.C. Centro(s) e periferia(s) das decisões no governo das escolas. Revista Portuguesa de Educação, Minho, v. 12, n. 1, p. 57-80, 1999.

LIMA, L.C. Administração escolar em Portugal: da revolução, da reforma e das políticas pós-reformistas. In: CATANI, A; OLIVEIRA, R.P. (Org.). Reformas educacionais em Portugal e no Brasil. Belo Horizonte: Autêntica, 2000. p. 41-76.

LIMA, L.C. Administração escolar: estudos. Porto: Porto, 2011a.

LIMA, L.C. Director de escola: subordinação e poder. In: NETO-MENDES, A.; COSTA, J.A.; VENTURA, A. (Org.). A emergência do diretor da escola: questões políticas e organizacionais. Aveiro: Universidade de Aveiro, 2011b. p. 47-63.

MACHADO, J. Escola, município e cidade educadora: a coordenação local da educação. In: COSTA, J.A.C.; NETO-MENDES, A.; VENTURA, A. (Org.). Políticas e gestão local da educação. Aveiro: Universidade de Aveiro, 2004. p. 161-172.

MENEZES, R.M. Processo de gasto e descentralização na política educacional brasileira. Em Aberto, Brasília, DF, v. 18, n. 74, p. 58-71, dez. 2001.

MONTAÑO, C. Terceiro setor e questão social: crítica ao padrão de intervenção social. 2. ed. São Paulo: Cortez, 2003.

NOGUEIRA, M.A. A dimensão política da descentralização participativa. São Paulo em Perspectiva, São Paulo, v. 11, n. 3, p. 8-19, jun./set. 1997.

OLIVEIRA, M.L. O papel dos conselhos municipais de educação na política educativa local. 2009. 123f. Dissertação (Mestrado) - Universidade Aberta, Porto. 
OLIVEIRA, R.P.; SANTANA, W. (Org.). Educação e federalismo no Brasil: combater as desigualdades, garantir a diversidade. Brasília, DF: Unesco, 2010.

PERONI, V.M.V. A relação público/privado e a gestão da educação em tempos de redefinição do papel do Estado. In: ADRIÃO, T.; PERONI, V.M.V. (Org.). Público e privado na educação: novos elementos para o debate. São Paulo: Xamã, 2008. p. 111-127.

PINHAL, J. Os municípios e a provisão pública de educação. In: COSTA, J. A.; NETO-MENDES, A.; VENTURA, A. (Org.). Políticas e gestão local da educação. Aveiro: Universidade de Aveiro, 2004. p. 45-60.

PINHAL, J.; DINIS, L. Aumento da autonomia das entidades locais. In: BARROSO, J. et al. Análise da evolução dos modos de regulação institucional do sistema educativo em Portugal. Lisboa: FPCE-UL, 2002. p. 15-31.

PIRES, C. A administração e gestão da escola do $1^{0}$ ciclo: o órgão executivo como objecto de estudo. Lisboa: Ministério de Educação, Departamento de Educação Básica, 2003.

PORTUGAL. Constituição (1976). Constituição da República Portuguesa de 1976. Diário da República, Lisboa, 2 de abr. 1976.

PORTUGAL. Decreto-Lei n. 141, de 26 de abril de 1993. Estabelece a orgânica das direções Regionais de Educação (DRE) como serviços regionais do Ministério de Educação que asseguram a orientação, coordenação e apoio aos estabelecimentos de ensino não superior. Diário da República, Lisboa, n. 97, Série I, 26 abr. 1993.

PORTUGAL. Decreto-Lei n. 115-A, de 4 de maio de 1998. Estabelece o regime de autonomia, administração e gestão dos estabelecimentos de educação pré-escolar e dos ensinos básico e secundário. Diário da República, Lisboa, n. 102, I Série - A, 4 maio 1998.

PORTUGAL. Decreto-Lei n. 7, de 15 de janeiro de 2003. Reativa os Conselhos Municipais de Educação e regulamenta as cartas Educativas Municipais. Diário da República, Lisboa, n. 12, I Série - A, 15 jan. 2003.

PORTUGAL. Decreto-Lei n. 75, de 22 de abril de 2008. Estabelece o regime de autonomia, administração e gestão dos estabelecimentos públicos da educação préescolar e dos ensinos básico e secundário. Diário da República, Lisboa, n. 79, I Série, 22 abr. 2008.

PORTUGAL. Lei n. 46, de 14 de outubro de 1986. Lei de Bases do Sistema Educativo Português. Diário da República, Lisboa, n. 237, Série I, 14 out. 1986.

PORTUGAL. Lei n. 31, de 9 de Julho de 1987. Ratificação do DL 125/82, de 22 de abril, que passa a ter nova redação (Conselho Nacional de Educação). Diário da República, Lisboa, n. 155, Série I, 9 jul. 1987. 
RIBEIRO, R.C.T. Conselho local/municipal de educação: da construção política do "local" à edificação jurídica de um espaço dito de participação contextualizada no campo educativo; constrangimentos e ambiguidades. 2005. 249f. Dissertação (Mestrado) - Faculdade de Psicologia e de Ciências da Educação, Universidade do Porto, Porto.

SANTOS, G. O conselho local de educação em agonia. In: COSTA, J.A.; NETOMENDES, A.; VENTURA, A. (Org.). Políticas e gestão local da educação. Aveiro: Universidade de Aveiro, 2004. p. 191-198.

SAVIANI, D. Sistemas de ensino e planos de educação: o âmbito dos municípios. Educação \& Sociedade, Campinas, v. 20, n. 69, p. 119-136, dez. 1999.

SOUZA, D.B. Os conselhos de acompanhamento e controle social: tendências municipais. In: SOUZA, D.B. (Org.). Acompanhamento e controle social da educação: os fundos e programas federais e seus conselhos locais. São Paulo: Xamã, 2006. p. 75-98.

SOUZA, D.B. Processos de gestão, autonomia escolar e órgãos colegiados nos Anais de eventos nacionais da Anped e Anpae (2000-2008). In: MARTINS, A.M. (Org.). Estado da arte: gestão, autonomia escolar e órgãos colegiados (2000/2008). Brasília, DF: Liber; Niterói: Anpae, 2011. p. 165-247.

SOUZA, D.B.; VASCONCELOS, M.C.C. Os conselhos municipais de educação no Brasil: um balanço das referências nacionais (1996-2002). Ensaio - Avaliação e Políticas Públicas em Educação, Rio de Janeiro, v. 14, n. 50, p. 39-56, 2006.

VIEIRA, S.L.; FARIAS, I.M.S. Política educacional no Brasil: introdução histórica. Brasília, DF: Líber Livro, 2007.

Recebido em 10 de maio de 2012.

Aprovado em 17 de outubro de 2012. 